NATURE INDEX I SCIENCE INC.

\title{
FIRST AMONG EQUALS
}

Exploring complementary strengths is the key to success in industry-academia science partnerships.

BY MARK ZASTROW

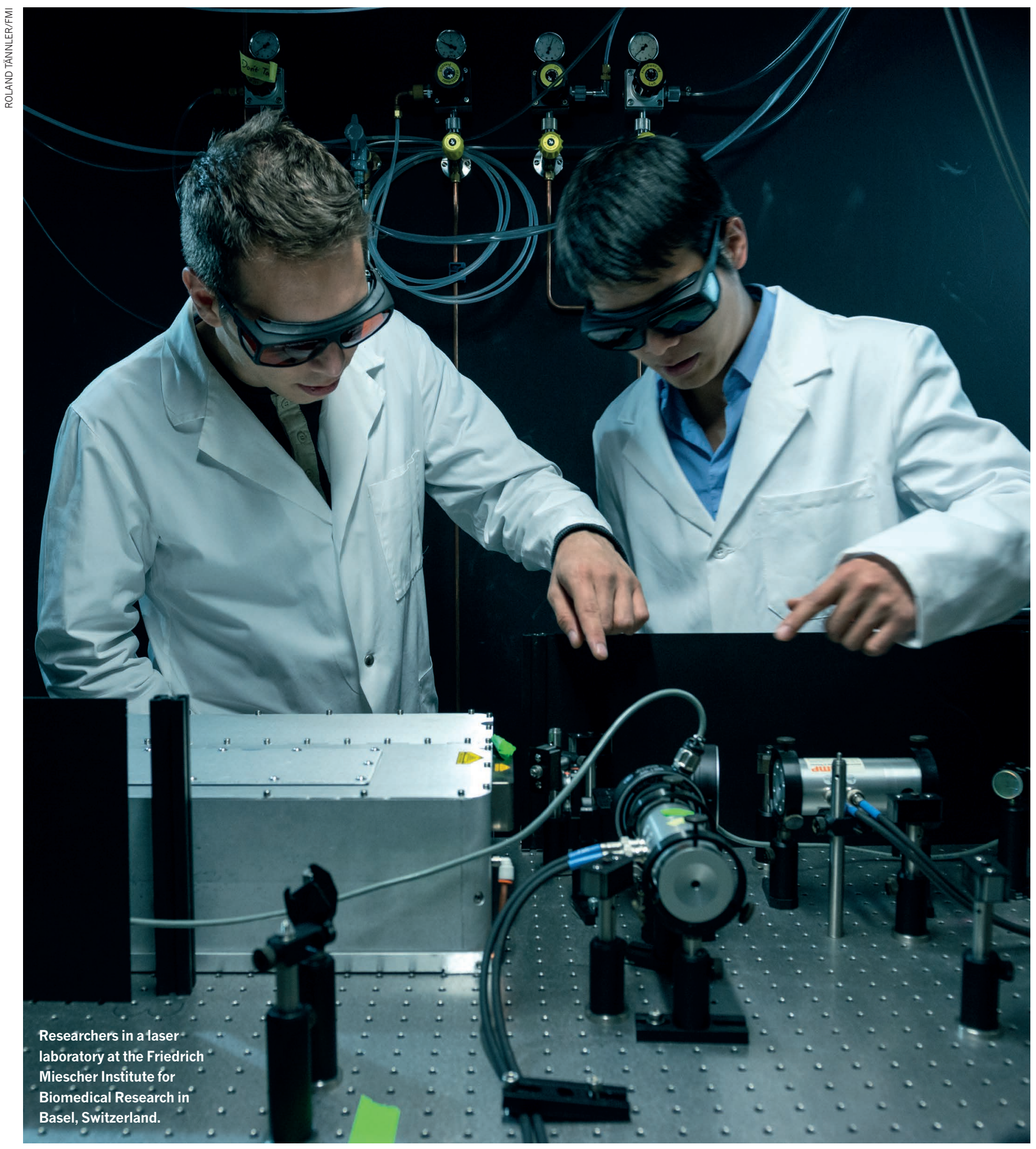


S cientific collaborations between companies and universities are often most productive when the partners function as equals. When each side capitalizes on the sometimes contrasting strengths of the other to advance understanding of fundamental principles, the results can find their way into hospitals, schools and homes.

Here, we examine the top academic-industry partnerships as measured by their share of the authorship in papers appearing in the

\section{NOVARTIS INTERNATIONAL AG \& UNIVERSITY OF BASEL: COLLABORATION SCORE (CS) 105.3}

The University of Basel (UB) and the global headquarters of Novartis are a kilometre apart on the banks of the Rhine. But the key to their partnership lies on the other side of the river: the Friedrich Miescher Institute for Biomedical Research (FMI), an independent institution with longstanding ties to both the university and the pharmaceutical giant.

FMI was jointly founded as a basic research lab in 1970 by two of the three Basel-based drug companies, which eventually merged to form Novartis. Today, it receives roughly $70 \%$ of its Nature Index from 2012 to 2016.

funding from the Novartis Research Foundation and remains affiliated with the company's in-house lab, the Novartis Institutes for BioMedical Research (NIBR). Students at FMI take courses and receive degrees at the University of Basel, where FMI group leaders also teach and advise students as adjunct faculty.

Its contribution is impressive: FMI researchers were co-authors on close to $90 \%$ of the 191 papers in the Nature Index from 2012 to 2016 with collaborations between Novartis and University of Basel-affiliated researchers.

Novartis reviews FMI's research portfolio every year and has first right of refusal on any intellectual property. But FMI and its researchers set their own agenda, says molecular geneticist, Antoine Peters.

Peters is planning a project with researchers at the University Hospital Basel and other Swiss institutions to study people conceived by assisted reproductive technologies such as in vitro fertilization, and whether the vastly different environment from the womb affects genetic expression.

Susan Gasser, director of FMI, says that its existence should be taken as a measure of Novartis' commitment to the Basel life sciences community, and to research "as a driver of innovation in the company, rather than buying in from biotech."

TOP 10 JOURNALS FOR NOVARTIS INTERNATIONAL \& UNIVERSITY OF BASEL

This graph shows the top 10 journals in which Novartis has co-authored papers with the University of Basel and Harvard University, as tracked by the Nature Index between 2012 and 2016. The collaboration score sums the partnering institutions' share of authorship in papers for each journal.

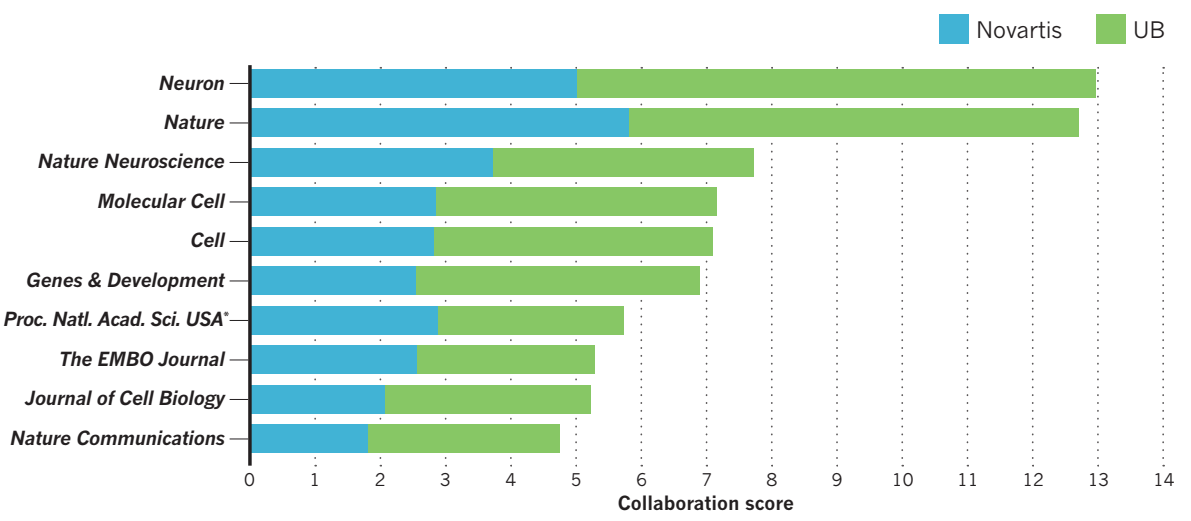

TOP 10 JOURNALS FOR NOVARTIS INTERNATIONAL \& HARVARD UNIVERSITY Novartis Harvard

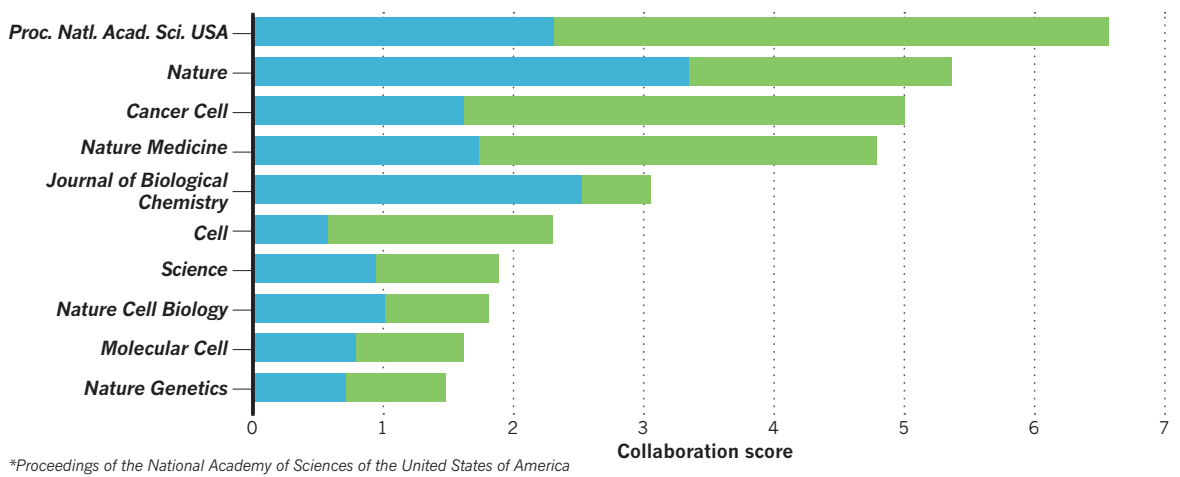

\section{NOVARTIS INTERNATIONAL AG \& HARVARD UNIVERSITY: CS 4.6 .2}

Novartis has more than 300 academic collaborations in its global research portfolio, according to a company spokesperson, which includes another trans-river pairing between Harvard University's medical campus in Boston and NIBR's global headquarters in Cambridge, across the Charles River. The pair of institutions has produced a steady stream of research, including 83 papers in the Nature Index from 2012 to 2016 - the third most prolific academic-industry partnership.

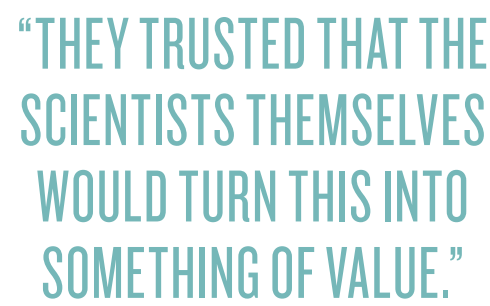

Collaborations with Harvard offer exposure to ideas from different fields, says Feng Cong, the director of the chemical biology and therapeutics department at NIBR's global headquarters in Cambridge, Massachusetts. He works regularly with Marc Kirschner, a systems biologist at Harvard, who models biological systems with computer simulations.

Theirs is one of several collaborations between Novartis and labs at Harvard's systems biology department, under an arrangement that Kirschner helped establish a decade ago, when he served on a Novartis advisory board. He says Novartis was not only looking for new drugs, but also took a serious interest in their basic research and methodologies. "They trusted that the scientists themselves would turn this into something of value."

Novartis also works extensively with the Broad Institute, a partnership between Harvard and the Massachusetts Institute of Technology in Cambridge. The Broad Institute was the origin of a Harvard-Novartis collaboration examining how the Zika virus attacks the brain of developing fetuses. Scientists had suspected that it latched on to the surface of nerve cells via the protein AXL. But in a 2016 paper, Harvard and Novartis researchers working with brain organoids found that genetically disrupting AXL did not protect against the virus - evidently, it can take alternative routes into nerve cells.

The two Novartis hubs will soon be even more tightly linked: in 2016, Novartis announced it would concentrate more of its global research in Basel and Boston, including establishing a chemical biology and therapeutics team - using CRISPR and other cuttingedge technologies - to be jointly based in Basel and Cambridge, Massachusetts. 


\section{SAMSUNG GROUP \& SUNGKYUNKWAN UNIVERSITY: CS 56.2}

Sungkyunkwan University (SKKU) and Samsung are more than research partners: in 1996, the conglomerate acquired the university. It's not for nothing that South Koreans sometimes refer to SKKU - founded in 1398 as the highest institution of learning under the Joseon Dynasty - as Samsung University. Today, Samsung, which makes up 13\% of the nation's gross domestic product, reportedly invests 100 billion won (US\$88.4 million) in the school every year.

Globally, there are examples of technical universities owned or operated by corporations, especially oil companies - Universiti Teknologi Petronas in Malaysia, owned by the nation's national oil company; and the King Abdullah University of Science and Technology in Saudi Arabia, initially built and run by Saudi Aramco. And in Korea, the Pohang University of Science and Technology was originally founded by the steel company POSCO. But SKKU is unique for being a longstanding institution that sought to enter into such a far-reaching arrangement.

Ties between Samsung and SKKU date back to the 1960s, but the company's 1996 acquisition was driven by Samsung's desire to move into the medical field, and SKKU's intent to open a medical school. The Samsung Medical Center opened in 1994 and became SKKU's teaching hospital in 1997. Today, it is responsible for a significant portion of SKKU-Samsung research output in the Nature Index, along with materials and nanotechnology research. The two institutes have together published 105 papers in the journals included in the index over the past five years.

"Samsung has supported SKKU in many ways beyond research," says Hong-Hee Won, a computational biologist at SKKU's Samsung Advanced Institute of Health Sciences and Technology, located at Samsung Medical School's campus in Seoul. Samsung's funding for scholarships and new buildings, as well as the reputation of the brand itself, has attracted quality students to the university, he says.

In return, Samsung is able to recruit graduates - researchers from its science and engineering schools, and managers from its business school - who have taken curricula tailored for the company's needs. It also guides the university's applied research agenda, creating entire institutes that align with its long-term strategic vision.

But what Samsung gives, Samsung can take away. This has been the case with graphene, the super-strong, conductive material that has long been of interest to Samsung's electronics arm. In 2010, it set up a joint graphene research centre in the SKKU Advanced Institute of Nano Technology, with some university research groups receiving US $\$ 2$ million per year.

In 2014, SKKU and Samsung researchers
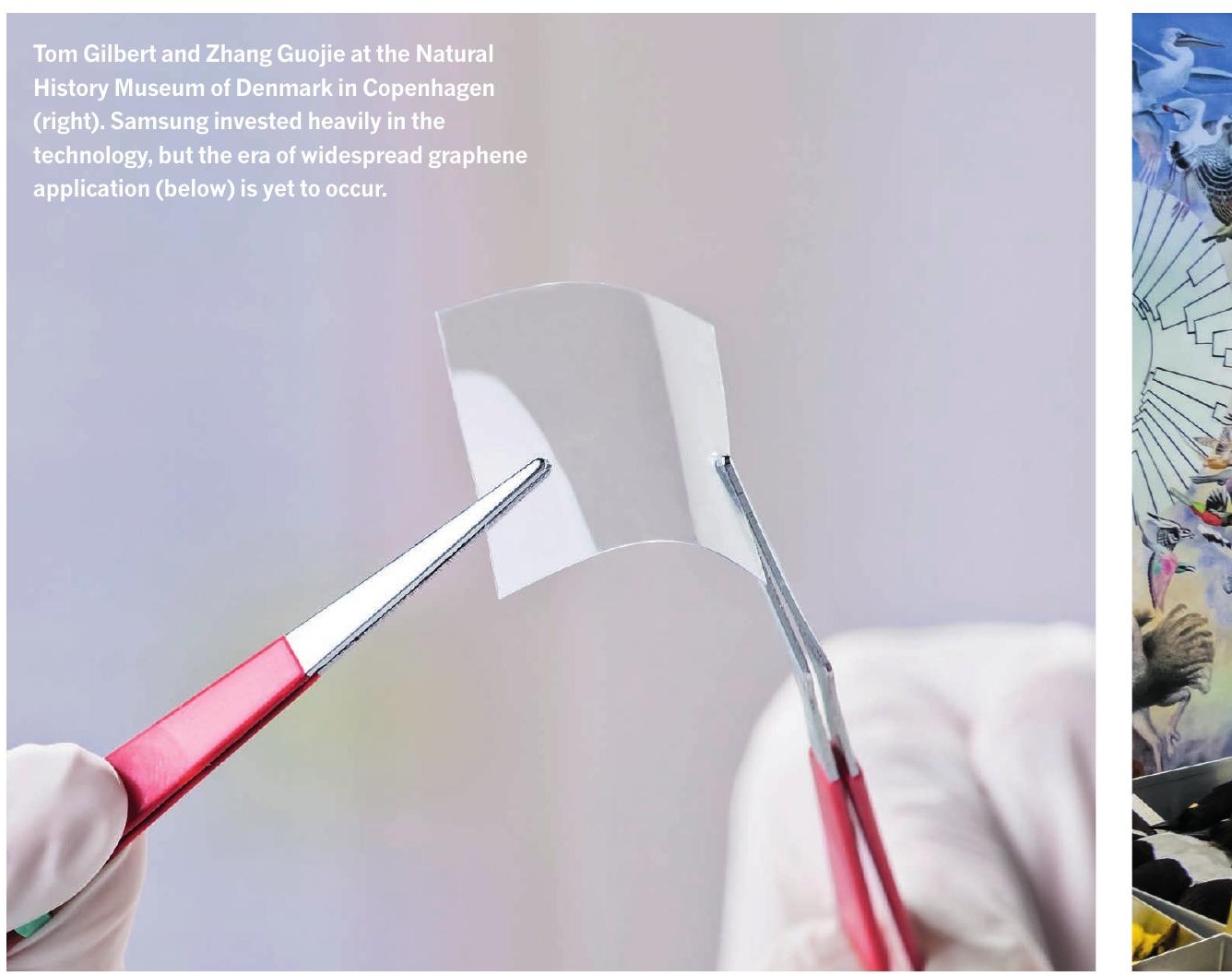

made headlines with a new production method that synthesizes graphene on top of a reusable layer of germanium, which guides the crystal growth to keep the structure uniform. The resulting graphene forms a single crystal big enough to be useful in electronics. The study was published in Science.

"We expect this discovery to accelerate the commercialization of graphene, which could unlock the next era of consumer electronic technology," Samsung researchers said in a company statement at the time.

But that era has not yet materialized, as

the company - and the rest of the world struggles to find commercial applications for graphene.

Today, joint graphene research between SKKU and Samsung has all but ceased and the centre has been effectively discontinued, says one researcher with knowledge of the situation who asked not to be named. In the researcher's opinion, Samsung "does not intend to industrialize graphene in the next one or two years." Samsung continues to research the material at the Samsung Advanced Institute of Technology, an in-house lab in Suwon.

\section{TOP 10 JOURNALS FOR SAMSUNG GROUP \& SUNGKYUNKWAN UNIVERSITY}

The two institutions contribute a relatively even share to the authorship of papers they publish together, as tracked by their contribution to the Nature Index between 2012 and 2016 . The collaboration score sums the partnering institutions' share of authorship in papers for each journal.

Samsung Group Sungkyunkwan University

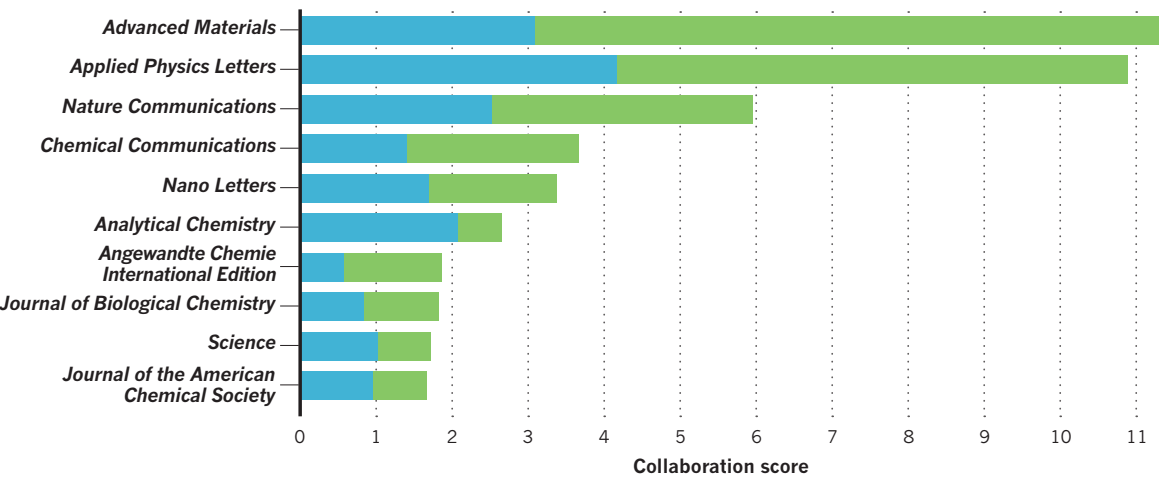


